\title{
INFLUENCE OF CAPACITY RESTRAINT FUNCTIONS ON TRAFFIC DISTRIBUTION AND THEIR PRACTICAL USE IN THE TRAFFIC MODELLING
}

The article deals with the issue of capacity restraint functions (curves) determining for roads and their use in the transport model. It describes the procedure for obtaining traffic flow characteristics and the derivation of the parameters needed to create basic restraint BPR function (Bureau of Public Roads). New parameters were then used in traffic assignment process. The impact of parameter changes for routes redistribution on traffic network was evaluated in detail.

The practical use of BPR function in the real traffic model is described in the second part. The article presents the method of volumedelay function definition for different model links types.

\section{Introduction}

Traffic assignment is the fourth and last major step of the traditional four-step process of transport modelling. This includes assignment of vehicle and person trips. The assignment of trips to the network is the final output of the modelling process.

Historically, highway and transit assignment procedures were used primarily for system analysis of large scale transportation improvements. A single volume-delay function for all facility types of roadways, the Bureau of Public Roads (BPR) curve, was used to estimate link travel times resulting from the assigned volumes. In recent years, a number of enhancements have been made to the process, due in part to increases in computing power. Volume-delay functions have been developed for different facility types (freeway versus arterial, for example). The detail of the coding of the networks has increased dramatically, along with the associated reduction in the size of the traffic analysis zones. Better assignment algorithms (such as equilibrium assignment) and parameters have produced improved results [1].

\section{Volume delay function in general}

Volume-delay functions (VDFs) describe the speed-flow relationships in a travel demand model network based on the available link capacity. As traffic increases on the network, the resulting travel time and delay increase. In an effort to better represent delay due to congestion, some study areas estimate alternative volumedelay functions or construct speed-flow relationships based on observed data to achieve reasonable congested weighted speeds from the trip assignment mode [2].

In most traffic assignment methods, the effect of road capacity on travel times is specified by means of volume-delay functions $t(v)$ which expressed the travel time (or cost) on a road link as a function of the traffic volume $(\mathrm{V})$. Usually these functions are expressed as the product of the free flow time multiplied by a normalized congestion function.

$$
t_{v}=t_{o} * f\left(\frac{v}{q}\right), \text { where }
$$

$t_{o} \quad$ free flow time,

$V$ - volume,

$q$ - capacity (it may be full capacity, capacity on the level or saturation flow).

The function should have several conditions. For the formulation of VDF the conditions can be divided into two groups - mathematical and behavioural [3].

\section{Mathematical}

From the mathematical point of view, having in mind the system optimal principle, the function should be [3]:

- continuous,

- strictly increasing,

- non - negative.

\section{Behavioural}

Following facts should be kept in mind [3]:

\footnotetext{
* Martin Bartovic ${ }^{1}$, Marek Drliciak ${ }^{2}$

${ }^{1}$ Centre of Excellence in Transport Engineering, Civil Engineering Faculty, University of Zilina, Slovakia, E-mail: martin.bartovic@uniza.sk

${ }^{2}$ Department of Highway Engineering, Civil Engineering Faculty, University of Zilina, Slovakia
} 
- in urban traffic most of the trips are made everyday - users have a lot of experience with traffic conditions in different times of the day on different routes,

- the user can make also "on-time" decisions - if he sees there is a congestion on the street in front of him or when he hears about congestion on the radio, he can turn and choose another route,

- time spent in the congestion weighs much more for the user than travel time at an acceptable speed - the user is strongly forced to choose another route,

- free flow speed - ex definition as a speed without any disturbances on the road, it decreases after implementing the traffic lights, but many users choose a route having in mind the real free flow.

\section{Measurement of traffic flow characteristics}

The interdependence of the traffic flow characteristics as the speed $(S)$, volume $(V)$ and density $(D)$ is necessary for the derivation of the VDF function. It is not easy to obtain the mentioned characteristics by the traffic survey. It could be calculated from the continuity equation (equation 2). This equation includes speed and time gap of each vehicles.

$$
V(x, t)=S(x, t) \cdot D(x, t), \text { where }
$$

$V(x, t)$ - volume,

$S(x, t) \quad$ - speed,

$D(x, t)$ - density.
The measured data of traffic characteristics on Obvodova Street in Zilina are listed as a practical example. The measurements were performed continuously for a period of 168 hours from Monday to Monday in March 2009. Obvodova street is a two-lane for the adjacent settlement and civil amenities Fig. 1.

The radar equipment SR 4 (Fig.1) was use for measurement of the necessary traffic characteristics (traffic flow statics). The device operates on the principle of the Doppler phenomenon. The change of the wavelength (frequency) of electromagnetic or acoustic waves is caused by movement of the source and observer. It could capture a vehicle speed between 8 and $255 \mathrm{~km} /$ hour with the accuracy of $3 \%$ for the speed, $20 \%$ for a vehicle length and $0.2 \mathrm{~s}$ for a time gap.

During the survey a total sum of 66,700 vehicles was recorded. The greatest 24 hour volume was measured in the afternoon hours on Friday, 3/13/2009.

An example of graphical evaluation of the transport characteristics relationship for the single traffic flow (one direction) on the Obvodova Street is shown in Figs. 2-4.

The relations between traffic flow volume and density (Fig. 2), between speed and density (Fig. 3) and between speed and volume (Fig. 4) illustrate the large dispersion of calculated values. The measured data were statistically evaluated and thereafter customized by the obtained standard deviation $\sigma= \pm 0.13$ to the form $x \pm \sigma$. The traffic flow quality on the road during the survey was also evaluated based on the function course [5].
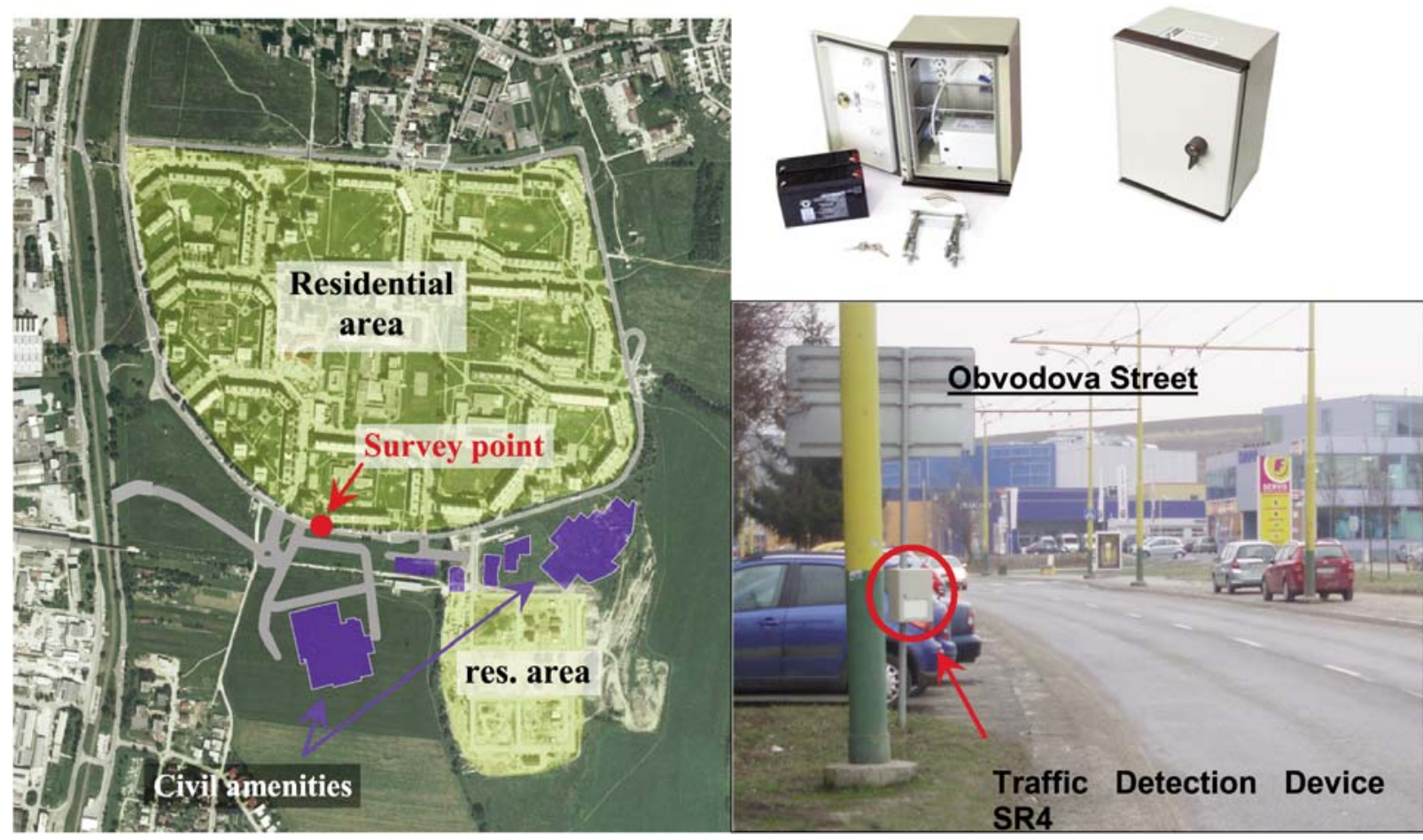

Fig. 1 Location of Traffic detection device SR4 on Obvodova Street 


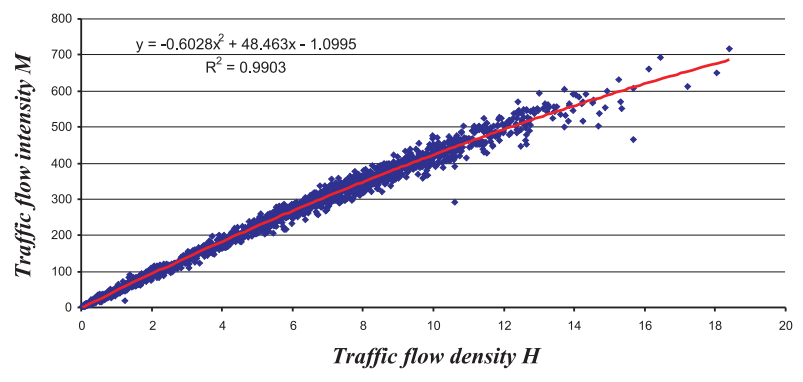

Fig. 2 Relation between traffic flow volume and density

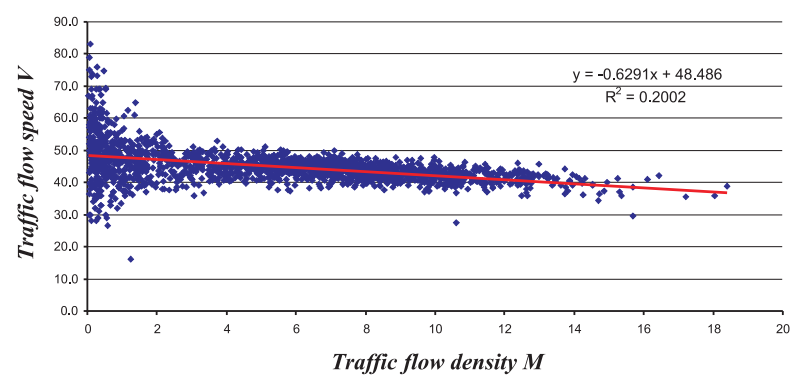

Fig. 3 Relation between traffic flow density and speed

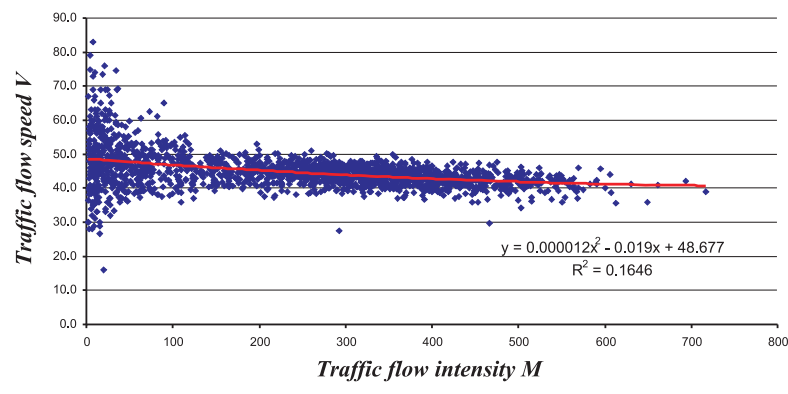

Fig. 4 Relation between traffic flow volume and speed

The function of the volume-density relationship has an increasing tendency. That means that the lane capacity was not exceeded

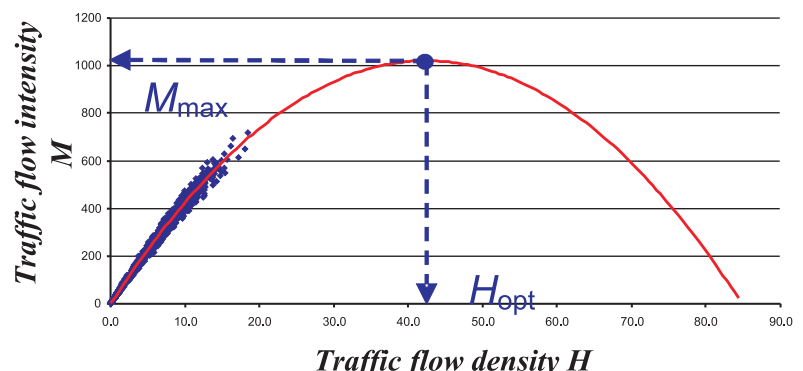

Fig. 5 Extrapolation of the relation between traffic flow volume and density

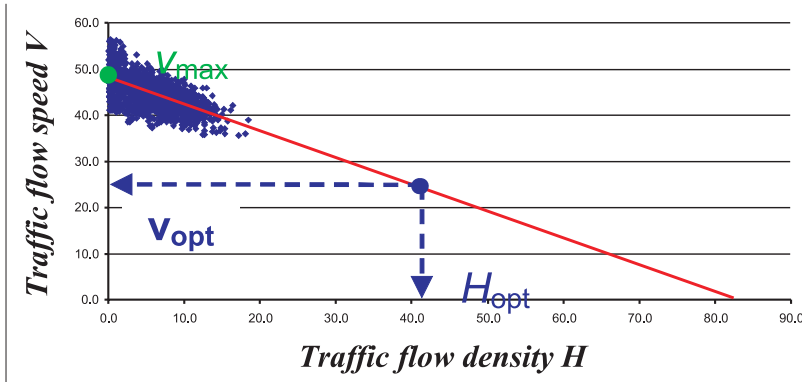

Fig. 6 Extrapolation of the relation between traffic flow speed and density

during the survey. The maximum volume was estimated by extrapolation of the calculated data (Fig. 5). In this case $V_{\max }$ is approximately 1000 vehicles per hour. The value of optimal density is $x$ coordinate of $V_{\max }$ point and it presents 42 vehicles per $\mathrm{km}$. The maximum (free flow) speed was set by extrapolation of the function of speed - density relationship. In this case $S_{\max }$ is approximately $48 \mathrm{~km}$ per hour (Fig. 6). The value $S_{\max }$ could be also obtained by using a regression equation of the trend curve.

\section{The determination of BPR function}

Many different types of volume-delay functions (or capacity restraint function CR-function, Fig. 7) were proposed and used in practice in the past. By far the most widely used volume delay functions are the BPR functions, which are defined as

$$
t^{B P R}(v)=t_{o}^{*}\left(1+a^{*} s a t^{b}\right),
$$
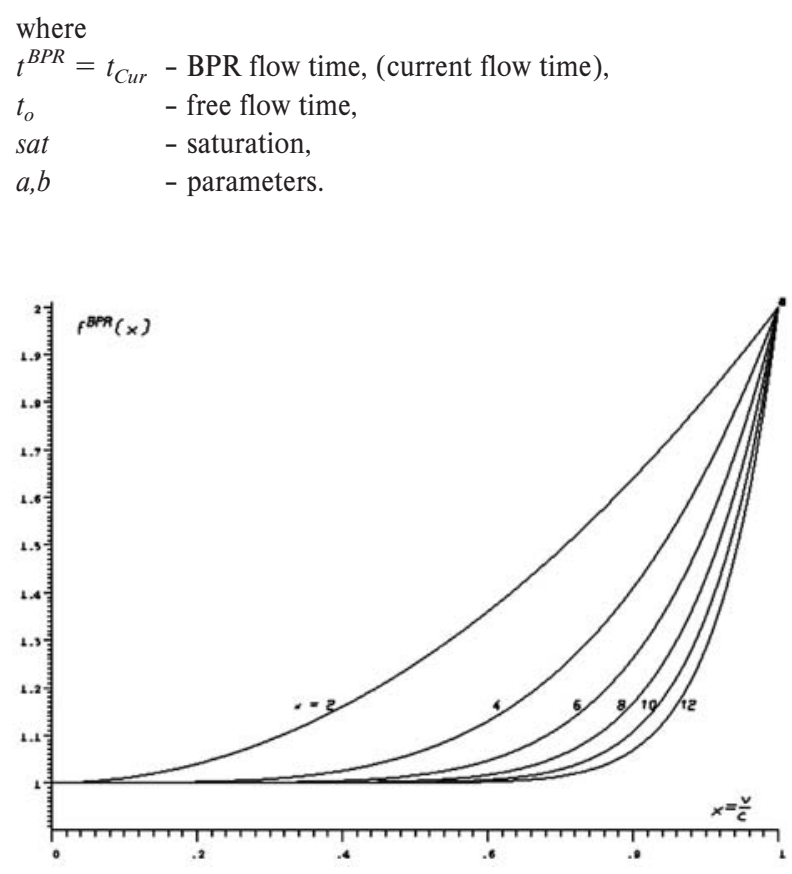

Fig. 7 Example of BPR functions for small $v / c$ ratios 
The volume-delay function, i.e. dependence of travel time on saturation, was processed according to the basic shape of the volumedelay function BPR (equation 3). This relationship is graphically shown in Fig. 8. The target trend line of calculated values is the looking volume-delay curve (capacity restraint curve).

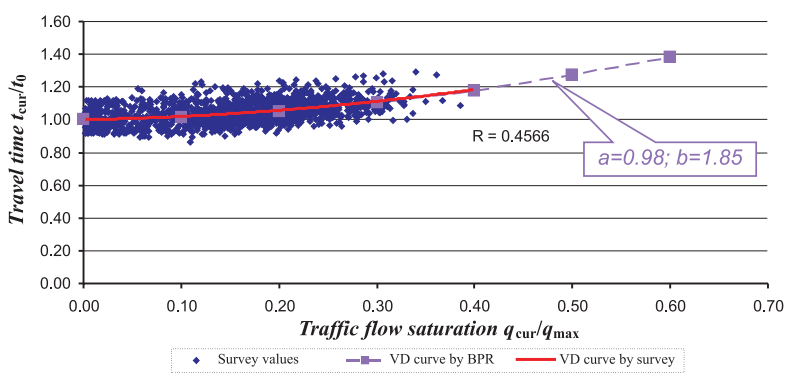

Fig. 8 Volume-delay curve after interval modifying to $x \pm \sigma$

Travel time was calculated based on equation (4):

$$
\frac{t_{c u r}}{t_{0}}=\frac{\frac{r}{s_{c u r}}}{\frac{r}{s_{0}}}=\frac{s_{0}}{s_{c u r}} \Longrightarrow \frac{t_{c u r}}{t_{0}}=\frac{s_{0}}{s_{c u r}}, \text { where }
$$

$S_{\text {cur }}$ - current vehicle speed,

$s_{0} \quad$ - free flow vehicle speed,

$r \quad$ - route length $=$ constant,

The values of parameters $\boldsymbol{a}$ and $\boldsymbol{b}$ of the trend line were found iterative. The value of parameter $\mathrm{c}$ was equal to 1 . The new found parameters are [5]:

$$
\boldsymbol{a}=0.98 \quad \boldsymbol{b}=1.85
$$

Traffic flow in the opposite direction was determined by the same process and the parameters of volume-delay curve were found [5]:

$$
\boldsymbol{a}=0.89
$$

$$
\boldsymbol{b}=2.11
$$

The results in this example show that the VDF (their parameters) are different not only for different types of routes, but also for driving directions.

The obtained results will be used in the transport model, in this case specifically in the PTV Vision-Visum program.

\section{Restraint functions in Visum}

VISUM is a program for computer-aided transport planning which serves to analyze and plan a transportation system. The transportation system includes private and public transport supplies (PrT and PuT) and travel demand. VISUM supports planners to develop measures and determines the impact of these measures.
In loaded networks, the link travel time and the turning time is determined by volume-delay function "VDF". This VDF describes the correlation between the current traffic volume $v$, and the capacity $q_{\max }$. The result of the VDF is the travel time $t_{\text {Cur }}$ in the loaded network. VISUM provides several types of volume-delay functions [4]:

1. the BPR function from the American Bureau of Public Roads (Illustration 28),

2. a modified BPR function with a different parameter $b$ for the saturated/unsaturated state,

3. a modified BPR function with an additional penalty parameter $d$ regarded for each vehicle in the saturated state,

4. the INRETS function developed by the French Institute National de Recherche sur les Transports et Leur Sécurité.

The time $t_{C u r}$ of a network object is calculated with volumedelay functions. Based on the assumption that the travel time (impedance) of network objects increases with increasing traffic volume, all assignment procedures are in turn based on the assumption that travel times of network objects are a monotone incremental function of traffic volume.

PTV-Visum program works with the default VDF setting as a function of BPR with the parameter values $a=1, b=2$ and $c=1$ for all types of roads. But it allows changing this setting and identifying the parameters for a previously defined road types (model calibration) - Fig. 9.

The links are defined as Global type $\left(0^{*}-9^{*}\right)$ or Types $(00-$ 99 ) in Visum. Every type of the link has attributes that have to be defined. Default values can be defined for the following attributes: name, rank, capacity - PrT in passenger car units, number of lanes, v0-PrT, vMin-PrT, transport system, max. speed and road toll by transport modes.

For example the traffic model of Zilina, which was created on the departmnet of highway engineering, has defined six main global types of links. We used only two types of the volume delay function with default setting. The optimal setting of all global link types is the question of many future measures (Fig. 10).

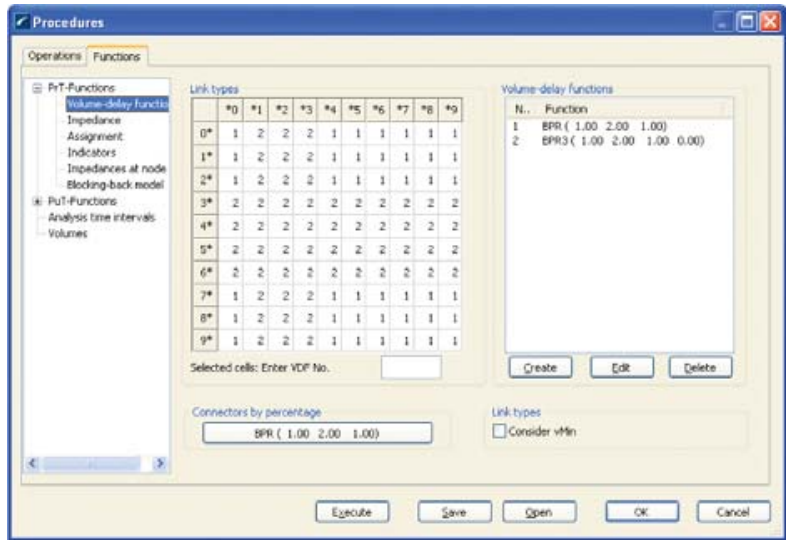

Fig. 9 Definition of volume delay function in PTV Vision -Visum 


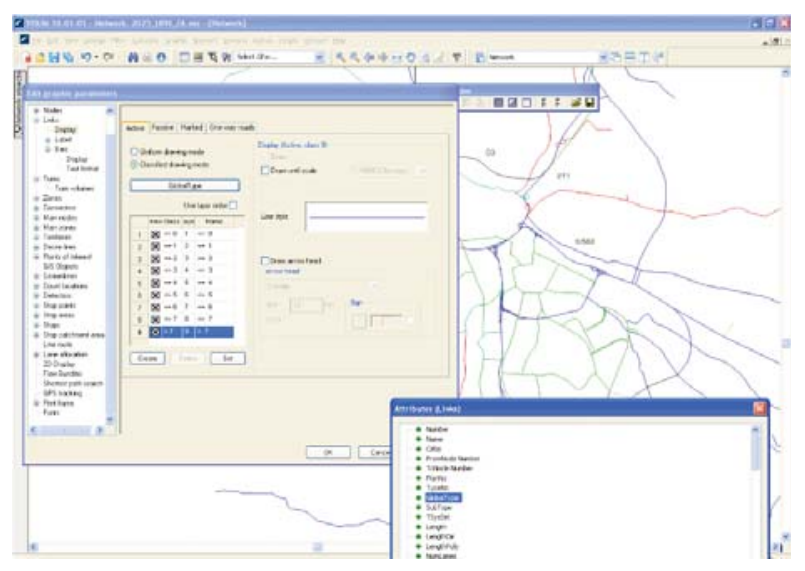

Fig. 10 Definition of global link type

\section{Conclusion}

The optimal setting of all attributes of the traffic model is a very difficult problem. The volume delay function is the main factor for calculation of real flow time. Sometimes the final results of traffic volumes are much higher than the capacity (over assignment). The new setting of parameters puts more exact values of the final capacity.

The Visum software allows defined impedance functions for links but it doesn't allow defined impedance functions for directions on the link separately. For this reason the model maker has to use the average values of impedance function parameters. The exact values of parameter could be specified only by a calibration process.

The impedance functions are very useful and important elements in the traffic assignment process and inseparable part of the calibration and validation process.

\section{Acknowledgement:}

This contribution is the result of the project implementation: "Centre of Excellence in Transport Engineering" (ITMS: 26220120027) supported by the Research \& Development Operational Programme funded by the ERDF.

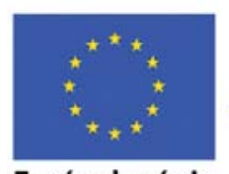

Európska únia

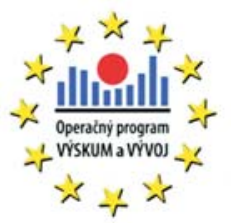

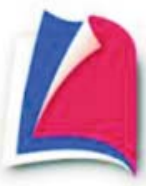

Agentúra

Ministerstva školstva, vedy, výskumu a športu SR

pre štrukturálne fondy EÚ

\section{References}

[1] Model Validation and Reasonableness Checking Manual - 7.0 Assignment Procedures; http://tmip.fhwa.dot.gov/resources/clearinghouse/docs/mvrcm/ch7.htm, US Department of Transportation,

[2] Speed Adjustments Using Volume-Delay Functions; - 7.0 Assignment Procedures; http://tmip.fhwa.dot.gov/resources/clearinghouse/docs/tmip/technical_syntheses/2009/january.htm, US Department of Transportation,

[3] JASTRZEBSKU, W. P.: Volume Delay Functions; $15^{\text {th }}$ Intern. EMME/2 Users's Group Conference; Vancouver, B. C.

[4] PTV_VISION Visum User Manual. Karlsruhe, 2002.

[5] BARTOVIC, M.: Modely delby prepravnej prace [Models for Division of Transport Work], Doctoral thesis, University of Zilina, 2009 (in Slovak). 